"These facts all point to the conclusion that in the majority of calcareous marine deposits, the Coccoliths originally formed a more or less essential part of the calcareous masses, and that in thick or granulous, and particularly ancient limestone rocks, they can no longer be perceived, either on account of the opaque character of the rocks, or because they have been made by some change wholly or in part unrecognisable, or have been altogether destroyed. I have been able by some experiments to throw further light upon this subject. That these smallest organic bodies can be recognised in hard limestones only in the rarest cases, even when it contains them in great numbers, I convinced myself by means of thin slices, which I made from Deep-sea Mud, thoroughly dried and rendered hard by repeated soaking in diluted Canada balsam and by heating, and also from writing chalk, made hard in the same way, and rich in Coccoliths The infinite numbers of finest granules and rings are so massed together, one over the other, that it must be regarded as an extremely rare case when a Coccolith is clearly seen here and there at the very thinnest edges."

\section{THE BRITISH ASSOCIATION}

\section{SECTIONAL PROCEEDINGS}

\section{Section A.-Mathematical and Physical Science}

On a new Electro-Magnetic Anemometer and the Modeof Using it in Registering theVelocity and Pressure of the Wind.-Mr. J. J. Hall.

The anemometer consists of two parts, viz, - velocity apparatus and registering apparatus. The first consists of a set of Robinson's hemispherical cups, which communicate their motion downwards into a brass box, where it is reduced in angular velocity, and causes a contact disc or commutator (in which two platinum contact pins are fixed equidistant from one another) to revolve in $\frac{1}{1}$ th mile. An insulated metallic lever, having a platinum working face, stands on either side of the disc, so that upon the completion of every $\frac{1}{50}$ th mile one or other of the rontact pins comes in contact with the two levers, thus uniting them and completing the circuit. The levers are raised a few degrees and then fall back to their normal position ready to be taken up by the next pin, and so on. The recording apparatus consists of a train of wheels and pinions working in a frame or between two brass plates, the arbors of which project through a dial-plate whereon the circles and figures are engraved and carry the hands. These wheels are driven by a weight attached to a line wound round a barrel, and a locking-pin disc (the pinion of which works in the frist wheel) is released at every contact of the cupapparatus by an electro-magnet which unlocks the pin-disc and allows the first hand to advance $\frac{1}{50}$ th mile on the graduated dial by a jump similar to the minute hands in remontoire clocks. By turning on a "strike-silent" stop a hammer lever is brought into connection with the escapement and strikes a bell at every contact. By this arrangement the observer has nothing to do but to notice the seconds-hand of his watch or chromometer while he counts the number of times that the bell is struck, each of which corresponds to the five-hundredth part of a mile, and by a formula arranged (and exhibited) by Mr. Hall (who has also arranged a comprehensive series of tables for use with this instrument) the hourly velocity may be readily deduced. In noting velocities extending over long periods of time, the instrument is read in the same manner as the ordinary cup and dial anemometer, or as a gas meter. By means of the formula before mentioned (although the unit of measurement in this instrument is five-hundredths) the observer may arrive at results as near the truth as if the instrument were capable of registering the one-thousandth part of a mile, while the great advantage lies in the fact that the battery power is less called into action, from which we may infer its elemental duration will be considerably longer.

A Magnetic Paradox. - Mr. S. Alfred Varley, Assoc. Inst. C. E. The author stated he had termed the instrument a Magnetic Paradox because the phenomenon exhibited by it was the apparent repulsion of soft iron by a magnet. The apparatus consisted of a compound magnet in a box, and when pieces of soft iron were placed on the box over the poles they became magnetic by induction and were attracted by the magnet; but if a soft iron bar not by itself magnetic was approached near to the pieces of iron, they leapt away from the magnet in the box and became strongly attached to the soft iron bar, the pieces of iron appearing to be repelled by the magnet and attracted by the fron bar. The author stated the explanation demonstrated the duality of the magnetic force, and it would also prove, did we not already know it, that magnetic force was transmitted only by induction. He stated that if a piece of soft iron were placed over the poles of a magnet, the magnet developes the magnetic forces resident in the iron by separating them, and the iron is altracted only by virtue of the forces existing in the iron itself, and to the extent to which the forces are separated. If the magnet be bent, bringing the lower pole round and over the piece of soft iron, the magnetic forces resident in the soft iron will be more developed : but if the piece of soft iron be midway, it will not be attracted, as the forces on either side are equal and balance; another attraction will, however, be manifested if one pole be nearer to the piece of iron than the other. If, instead of bending the magnet as just described, the piece of soft iron placed over the magnet be approached by a soft iron bar, the magnetic forces separated and rendered active in the piece of iron will develop the magnetic forces resident in the iron bar, and if the bar opposed no resistance to the assumption of the magnetic condition, it would exert an attractive force for the piece of soft iron equal to that exerted by the magnet, provided always that the bar was at the same distance. It was stated that as the mass of iron in the iron bar was much greater than that of the piece of soft iron, the resistance opposed by the bar to polarisation was comparatively small, and might be disregarded, and consequently it followed thit as the dual forces resident in iron are equal, and the one force cannot be developed without equally developing the other; when the iron bar was approached nearer to the piece of soft iron it became attracted, leaping away from the magnet and attaching itself to the iron bar, and this notwithstanding that the attractive force exhibited by the iron bar has been called into being by the magnet in the box, which is nearer to the piece of soft iron than it is to the iren bar. The iron bar also collected the magnetic rays of force issuing from the magnets, and consequently it exerted a greater attraction for the piece of soft iron than any individual magnet forming part of the compound magnet. This was shown by placing a piece of soft iron on the pole of one of the magnets and removing it from the pole by the superior attractive force of the iron bar. It was also shown that if only the thickness of a picce of writing-paper were placed between the magnets and the piece of soft iron, the appearance of repulsion could be prevented.

\section{Section B.-Chemical Science}

On the Separation from Iron Furnace Cinder of Phosphoric Acid for Minurial Purposes. - Mr. James Hargreaves. While the author was engaged in an attempt to produce a good serviceable steel direct from phosphoric pig-iron, by the use of nitrate of soda, the fact forced itseif upon his attention that phosphorus had previously been too much looked upon as something to be got rid of, and not sufficiently as sometling to be got hold of; and that to effect the latter would be the best means of effecting the former. When phosphoric pig-iron is converted into malleable iron, the phosphorus is, in great part, transferred to the refinery and puddling furnace cinder in the form of phosphate of iron, the amount varying with the composition of the pig-iron which yields it. The refining and puddling furnace cinder from Cleveland pig-iron generally contains from 3 to 7 per cent. of phosphoric acid, which is from one-fourth to one-half the amount contained in good commercial soluble phosphate of lime. This cinder is sometimes again used for the manufacture of pig-iron, but the product is of small commercial value on account of the accumulation of phosphorus in it. The concentration of the phosphorus from the pig-iron into the cinder in the form of phosphate of iron renders it more easy and practicable to separate, when the preparation of compounds of phosploric acid is the object in view, as there is a smaller bulk of material to be treated to obtain a given amount of this product. The phosphoric acid may be separated either in the form of soluble superphosphates of lime and magnesia, or of the alkaline tribasic phosphates.

On the Retention of Organic Nitrogen by Charcoal. - Mr. Edward C. C. Stanford, F.C.S. In this paper the author submitted some incomplete researches, as a first instalment of what promises to be a wide field of inquiry, viz., the action of char. coal on organic nitrogenous matter. He was desirous of knowing whether or not a loss of nitrogen occurs when that form of matter remains in contact with charcoal, and if so, what becomes of it. If any loss occurs, it would invalidate the process recommended by the author at the Exeter meeting of the Association, viz., that of using charcoal as a means of securing the 
whole value of town excreta. He said that he had shown last year that, with either fluid or solid excreta, there was no loss, as far as his experinients had then exiended; and te had poinled cut, also, that he expected no loss from oxilation, as both must already be regarded as oxidised compounds. His experiments since had extended over a long period, and he had included meat as one of the nitrogenous matters used; in all, however, he had found no loss of nitrogen, no oxidation, and no formation of nitrates.

\section{SeCtion C.-Geology}

On a Census of the Marine Invertebrated Fauna of the Lias.Mr. R. Tate. The author $g$ ave an analysis of the fossils, but desiderated more precise data before exact results could be obtained.

On the Formation of Boulder Clays and Alternations of Level of Land and Water.-Rev. J. Gunn. The author illustrated his own opinions, which were completely at variance with the generally accepted interpretation of the origin of these beds.

On Some Cases of the Recent Conversion of Glacial Drifts into what Appears to be Middle Drift. - Mr. G. J. Stoney.

On the Occurrence of Pebbles and Boulders of Granite in Schistose Kocks in Islay, Scotlund.-Mr. J. Thomson. The author described the different rorks exhibited in a section across Islay from west to east, and the position of the metamorphic rock in which the boulders nccurred which underlies a bed of quartzite seventy feet thick. Specimens of some of the smaller boulders with their interesting matrix still attached to them were exhibited. The bed probably indicated one of those recurring glacial epochs which had formed the subject of Mr. Wallace's communication to the section.

Diamonds of South Africa.-Professor Tennant.

Changes of Climate.-Mr. R. A. Peacock. These were due, according to the author, to rain and rivers, to rentudations, to risings and sinkings of land, and to the great range of temperature in interplanetary space and on the various parts of the earth's surface. The warm, genial climate of the Carboniferous period he ascribed to the absence of high hills at that time on the globe.

Sur le terrain Silurien du centre de la Belgrique.-Professor Malaise. The author described the series of beds with their fossil remains, and considered that they represented a portion of the Middle Silurians, more extensively developed in Belgium than in Britain.

On the Remains of an Insect discovered in the Curboniferous bedts at Huyton. - Mr. Clementshaw exhibited the specimen of the insect, and pointed out the characters upon which he ventured to refer it to the Fulgoride.

Notes on a Merionethshire Gold Quartz Crystal, and some Goia found recently in the River Marvddach.-M M. T. A. Readwin.

\section{SECTION D.-Biology \\ Department of Anatomy and Physiolooy}

On the Connection of the Hyoid Arch with the Cranium.Prof. W. H. Flower, F.R.S. In the sheep, as is well known, the anterior arch or cornu of the hyoidean apparalus is des. cribed as consisting of three bones, of which the uppermost is by far the largest and most important, and has received the name of stylo-hyal. This bone is long, compressed, and at the proximal end enlarges and divides into two short branches, by the anterior of which it is continued as a cartilaginous band to the cranium. The upper end of this band is again ossified in the form of a curved cylindrical plug of bone, with a truncated lower extrenity, lying in a grooye on the side of the tympanic bone, the erges of which groove meet around it in adult animals, and often become ankylosed with it ; but this is only a secondary connection. The primary connection is with the perictic or petro-mastoid bone, immediately in front and to the inner side of the stylo-mastoid foramen. In embryonic specimens it can be traced as a distinct band of cartilage lying to the anterior and inner side of the lower end of the Fallopian aqueduct, and passing to the upper and back part of the tympanic cavity, near to the spot from which the stapedius muscle takes origin. This is then the true proximal extremity of the anterior arch of the hyoidian apparatus, if we leave out of consideration the stapedius and incus which there is reason to believe are developed from the same rod of cartilage-a question which is not discussed in the present communication. Whatever may be the case with regard to the origin of the last-named parts, it is a subject of easy demonstration that in the sheep there is an ossified portion of the upper end of the hyoid arch, above and distinct from the stylo-hyal, which becomes firmly united with the periotic, and which may ossify either from a separate centre or by extension of bone from the perintic. Whether it should be considered as a process of the periotic or as a separate element may still be a matter of opinion; but the existence of such a part as a distinct portion of the hyoid arch requires recognition. It may be conveniently distinguished by the name of tympanohyal, as it is always in relation with the tympanic bone, and continues the hyoid arch up to the wall of the cavity of the tympanum.

This portion of the skull can be distinctly recognised at the spotin dicated (i.e. to the anteriur and inner side of the stylomastoid foramen) in alnost all mammals, though in very different degrees of development, usually in accordance with the size and amount of ossification of the remainder of the anterior arch. Thus, in those of the Ungulata, as the ruminants, and especially the horse and rhinoceros, in which the stylo-hyal is very largely developed, the tympano-hyal is most conspicuous, but where, as in the pig, the anterior arch is little ossified, the tympano-hyal is comparatively rudimentary. In the cetacea it is quite distinct, though small, and a fine band of cartilage can often be traced from the upper end of the stylu-hyal into it, embedded in the great ligamentous mass which attaches that bone to the exoccipital and surrounding parts of the cranium, and which of course is only a secondary connection.

In man, this bone or process is also quite distinct, although it seems to have been generally confounded with the stylo-hyal. The so-called styloid process of the temporal bone has long been known to have a separate centre of ossification, and is also gene. rally recognised as the homologue of the stylo-hyal of other mammais, one of the main points of difference being, that whereas in all others it is an independent bone not connected directly with the cranium, in man it is always ankylosed to the "tem. poral," or forms a process of the skull.

If a human skull at the period of birth is examined, a very small round piece of bone surrouncled by a deep grnove can be seen exactly where the tympano-hyal is found in the sheep, just behind the posterior limb of the inverted arch formed by the tympanic bone, and in front and to the inner side of the stylo-mastoid foramen. This increases somewhat in size as age advances, forming a distinct process, supported, and partly embraced in front by the vaginal process of the tympanic. The true styloid or stylo-hyal at birth is a slender rod of cartilage, often partially ossified in the centre, and invested by a strong fibrous sheath, from which the stylo-hyoid, stylo-glossus, and stylo-pharyngens muscles take origin. Though it occasionally becomes ankylosed in the adult with the tympano-hyal, as is the case with thuse skulls which have very long styloid processes, this does not occur so frequently as is described in most works on anatomy. In the large majority of skulls, before middle age, the stylo-hyal is free, and is commonly lost in maceration. The short process which is always present, and which is commonly considered as a rudimentary styloid process, is $r \epsilon a l l y$ a distinct portion of the hyoid arch, corresponding with the tympano hyal of the sheep.

The communication was illustrated by specimens and diagrams.

On the Correspondence between the Anterior and Posterior Extremity, and the Modifications of the Position of the Limbs in the higher Veltebrata. - Professor W. H. Flower, F.R.S. This cummunication was chiefly devoted to an exposition, by means of specimens and diagrams, of the views held by most English anatomists of the serial homologies of the different bones of the extremities, founded upon comparison of the anterior, cephalic, or preaxial border of the one, in the primitive position, with the same border of the other, which leacts to results opposed to the views of Wyman and other American anatomists, founded upon the principle of antero-posterior symmetry.

On Lefthandedness.-Dr. Pye-Smith. The author referred to the prevalence of this condition as an occasional variety as far back as tradition goes, and in various parts of the world. Like righthandedness, it should be regarded as a functional specialisation, not a structural transposition. That it does not depend on transposition of the viscera is proved by several cases ; and also that it does not result from the abnormal origin of the subclavian artery, as referred to in a previous number of NATURE. Righthandedness is probably the inmediate result of some struc$t u$ al difference between the two cerebral hemispheres. Gratiolet's statement, that the left hemisphere is earlier developed, is con- 
tradicted by Ecker, Vogt, and Callender ; but Broca's, that it is normally heavier than the right, is confirmed by Dr. Boyd. The author then spoke of the possible truth of Brown-Séquard's theory of the left hemisphere presiding specially over animal, the right over organic functions. Nurmal aphasia with riglst hemiplegia was contrasted with cases cited from Dr. Ogie and Dr. Hughlings Jackson, of left-handed persons with lett hemiplegia and aphasia. The primitive condition was probably one of perfect bilateral structural symmetry and ambidextrous function. The normal condition at present is the result of hereditarily transmitted specialisation of structure and functions, both the resul: of some advantage resulting to individuals using the right hand, eye, or foot, for the performance of more specialised functions than those of swimming, climbing, \&c., such for instance as carrying weapons or nursing children. Lefthandedness would then be explained as a more or less complete reversion to an ancestral condition. Right and Lefthandedness should, therefore, be compared with such deviation in function and structure as is observed for instance in the clelæ of the higher Crustacea, while transposition of viscera is to be classed with the reversed twist occasionaliy seen in the skull of Pleuronectides and the shells and entire bodies of Gasteropoda.

Professors Burdon Sanderson and S. Stricker read a paper on A New Method of Studying the Capillary Circulation in Mammatia. The circulation was studied in the omentum of a guinea-pig immersed in a solution of salt and water of a certain strength and temperature, the animal being thoroughly chloralised.

Contributions to the Migration Theory.-Richard Caton, M.D. This paper contained an account of a number of experiments on the capillary circulation of the frog, fish, and tadpole in reference to the interesting phenomenon of the migration of blood-corpuscles out of the vessels. The opinion was expressed that this occurrence was chiefly due to congestion, and also that there were grounds for considerable doubt as to whether it had any connection with the suppurative process, as hitherto supposed to be the case. This paper was read immediately after those of Dr. Burdon Sanderson and Prof. Stricker, and the three were discussed together.

On the Antiseptic Treatment of Contagia as Illustrative of the Germ Theory of Disease.-Mr. Hope. The anthor gave some valuable details as to his treatment of the rinderpest which broke out upon his experimental farm in Essex in 1867 . The majority of between 260 and 270 cows were attar.ked by that disease. He injected carbolic acid through either the mouth or rectum, and II I of those cows so treated recovered. The remainder not so dealt with died or had to be slaughterer. He also argued that the chemical instead of the medicinal treatment of contagion was much better both in respect to men and the lower animals. He also gave illustrative cases of scarlet fever, with the view of showing that the sipping of a very weak solution of carbolic acid, sprinkling bodv, clothes, carpets, \&c., was highly beneficial in its effects.-Dr. Baylis, medical officer of health, Birkenhead, agreed with the reader in his views regarding rinderpest, but not entirely with his treatment of fever. He (Dr. Baylis), speaking of the unsatisfactory manner in which that subject was treated by the British Association, expiessed a hope that before next year's meeting they would institute some experiments as to the action of disinfectants.

\section{Department of Ethnology and Anthropology}

Dr. King read a paper On Blight in Man, and the Animal and the Vegetable World. Having defined the terms blight, contagion, and infection, the author proceeded to describe the signs by which their presence could be traced, and enumerated the various diseases which were supposed to be contagious or infectious, referring incidentally to small-pox, which could not, in his opinion, be averted by vaccination. He thought that disease was the result of a local impurity of the atmosphere, and that whereas a healthy person might be affected if he went to the locally impure spot, the party suffering could not convey it to another upon his removal to a different locality.

Dr. Hitchman read a papei on the Anatomy of Intellect, detailing numerous physiological experiments in regard to the nature of life and mind in man and animals. Mental phenomena, he maintained, did not always imply the existence of brain, or cephalic ganglia, or of nerves conveying impressions to cerebral organisation at all. Mind is not invariably dependent upon a molecular condition of brain-this organ being often sound in acute and chronic cases of insanity, the seat of disease being found, according to statistical observation, at home and abroad, in the alimentary canal, liver, uterus, spleen, heart, and lungs, in at least a moiety of all cases. This is true, even in the must severe mental affection known to the physician, paralytic dementia. The mental principle is not confined to brain molecules, but is equally contained in parts far distant from them, and is separable from the body, as mind, in a latent state, as well as an inmaterial new individual. The whole mental organisation is specially operant independently of all molecular changes in ganglious and nervous cords, though the psychical mode of action is largely determined in the genus homo and higher forms of animal nature, by the modification of structure and physiological condition of each anatomical organ; both healthy and morbid changes show there is a certain point in the physical history of instinct and intelligence, at once and for ever fatal to the doctrine of Professor Tyndall, and other physicists, viz., that thought, sense, emotion, nay, every fact of consciousness, are due exclusively to molecular motions of brain.

On the Relation of the ancient Moabites to neighbouring Nations, as disclosed in the newly discovered Moabite Stone.-Rev. Dr. Ginsburgh. This stone was found as recently as the year I 868 , during researches in Palestine; the inscription occupied 34 lines, and was written in a language which traced its origin to a date long prior to the Christian era. The translation looked like a chapter of the Bible; and when it was burne in mind that of $I_{5}$ cities mentioned in the Old Testament, II were referred to on the stone, no one could duubt that the Moabites were in a far greater state of civilisation than was generally supposed. The inscription dated back as far as 900 years before Christ, and was, therelore, older than two-thirds of the Old Testament. As the result of careful study, he came to the conclusion that an organised Temple service was observed amongst the Jews out of Palestine, and that that service must have been very much akin to the service of the Muabites; that at a period goo years before Christ, the word "Jehovah"--although subsequently avoided with so much persistency - was so often upon the lips of the Hebrew race, that it passed over to a neighbouxing nation; that the simplicity of the language was a striking evidence of the advanced stage of civilisation of the Woabites, and that in prowess they were superior to the Jews.

The following papers were read relating to the Australians, their language, and mental characteristics. The first paper was by Mr. C. S. Wake, and was entitled, The Physical Characteristics of the Australian Aborigines; the second was sent by Dr. Bleek, and was on The Fosizion of Australian Languages. The author traced certain analogies between the several Australian languages, placing then all in $\mathrm{Max}$ Müller's great nomadic or Turanian class; and although the Australians have, with few exceptions, no grammatical distinctions of gender, the author does not think that this necessarily excludes them from the sex-denoting family. The use of suffixes in the Australian languages led him to infer that they have been derived from the more temperate zones. Indeed, the nations using suffix -pronominal languages are found on the outskirts of the tropics, and in temperate and cold latiturles, while those speaking prefix-pronommal tongues are restricted to the tropics; and ayain, the suffix-pronominal class are addicted to sidereal worship, and the prefix-pronominal to ancestor worship. The author, however, carelully showed that the physical descent of a race by no means necessarily coincides with the descent of its language ; and, in conclusion, the leamed doctor expressed his belief, based on a study oi the mythology and the present customs of the Australians, that these have degenerated from a higher state of civilisation. The third and concluding paper in this series was by Mr. C. S. Wake, and was on The Mental Characteristics of the Australian Aborigines.

\section{Section G.-Mechanical Scrence}

Rolling or Shaping Axles:-Mr. Alfred Bowater. This paper embrace a description of a new machine, existing in model, for the shaping of railway axles by rolling pressure. Whereas by the meihod of using the steam hammer an axle required half an hour in shaping this rolling process would effect it in a superior manner in two minutes. The rolled axle was not only superior in quality, but was more uniform in size, and coulci be produced much more cheaply. The machine consisted of three rollers, which were reguldted so that they might gradually press closer together, thus reducing the diameter of the bar and extending 
its length until shaped to the size required. Axles of any length could be rolled by the machine, with collars at any part of the tyre. The rollers were geared to revolve all in the same direction, and their friction imparted motion to the axle. The rolling process would obviate those flaws in axles which occasionally caused appalling accidents on railways.

On a New Safety Lamp.-Mr. W. E. Teale. After detailing a number of the objectionable features of the various safety lamps now in use, the author proceeded to say that, with a view to remedy so far as possible the dangers arising from the insecurity of the present oil lamps, the Protector Colliery Lamp has been carefully and thoughtfully designed to combine safety and brilliancy of light with cleanliness and economy. It is made on the principle of the ordinary sponge or portable gas lamp, in which is used a liquid specially prepared by the inventors. The reservoir, or gas-holder, is then screwed to the top of an ordinary Stephenson or Clanny lamp, within which are fixed a pair of horizontal hinges, moving upwards only. On the wick tube of the lamp, and sliding over it, is an outer tube, having round its centre a circular horizontal flange. When the reservoir is screwed upwards into the top, this flange comes into contact with the hinges, raises them in passing, and allows them to fall beneath it when screwed home, so that by reversing the screw, and withdrawing the reservoir gradually from the top, the said hinges prevent the return of the said sliding tube, thereby forcing it over the wick-tube, and so diminishing, and ultimately extinguishing the light. It is therefore impossible for a naked light to become exposed after the lamp has once been adjusted. To render security doubly sure, a lock and stop are so placed that after the light is put ont by the action of the screw, it is still impossible for the collier to withdraw the reservoir from the top, so as to re-light his lamp. The safety of the mine is further insured by the fact that the gauze is kept perfectly clean, and therefore no coal-dust can adhere to it, as in the old oil lamps. In regulating and reducing the light when testing for gas, which can be done with the greatest ease and certainty, no pricker is used or required, and another source of danger is avoided. This lamp burns freely with less ventilation than any now in use, and is much more sensitive to the presence or action of gas, while it is impossible for the miner to light his pipe from, or tamper with, the light in any manner. It gives much more light than that produced by the very finest oil; and as neither smoke nor soot is made by combustion, the glass and gauze are as clean and the light as good at the end of the day as when the miner goes down the pit, and this without the trouble and great loss of time necessary to keep an oil lamp properly trimmed. As compared with oil, the cost of burning the Protector Colliery Lamp is very small, six days of ten hours each, or sixty hours, being obtained at a cost of threepence, or less than one half the price of ordinary miners' candles, and one-third that of the usual oil.

On Ocean Telegraphy. - Captain Rowett. The object aimed at in his paper by Captain Rowett was to show the superiority of hemp over metallic cables. The author contended that hemp cables were much lighter and extremely enduring when submerged, and iron cables were quickly corroded by the action of the sea water. Various specimens of submerged cable were exhibited by the author in support of his views.

\section{SCIENTIFIC SERIALS}

Fournal of the Chenical Society, September, 1870.- This number only contains two papers ; the first, on Vapour Densities, by Mr. J. T. Brown, contains a short description of the methods that have been proposed for their determination, and the formula employed for calculating the results from the data obtained. This serves as an introduction to a series of elaborate tables intended to facilitate these complicated caiculations. The tables are a sequel to some previously published by Mr. Brown (Fourn. Chem. Soc. N.S. iv. 72), and it might be acceptable to many chemists if the author would collect these and other tables and publish them in a separate pamphlet. The other paper is an abstract of a memoir in the Philosophical Transactions for 1869 , entitled "Researches on Vanadium," by Professor Roscoe. The author has obtained three vanadium chlorides, a tetrachloride $\mathrm{V} \mathrm{Cl}_{4}$, a trichloride $\mathrm{V} \mathrm{Cl}$, and a dichloride $\mathrm{V} \mathrm{Cl}_{2}$. The tetrachloride may be prepared by passing dry chlorine over the mononitride heated to redness, or by transmitting a mixture of chlorine and the vapour of vanadyl trichloride $\mathrm{V} \mathrm{O} \mathrm{Cl} 3$ over red-hot suyar-charcoal. Its vapour density corresponds to the formula $\mathrm{V} \mathrm{Cl}_{4}$. The trichloride is a crystalline peach-blossom coloured compound, resembling chromium sesquichloride. It is not volatile in hydrogen, but when strongly heated in this gas it loses chlorine, the dichloride and finally the metal being obtained. It is produced by heating the tetrachloride, or by its slow decom. position at the ordinary temperature, or by passing its vapour with hydrogen through a red-hot tube. Vanadium dichloride is an apple-green crystalline body, prepared by transmitting the vapour of the tetrachloride with hydrogen through a tube heated to dull redness. The dichloride, when heated in hydrogen in a platinum boat, yields the metal in bright, greyish-white lustrous grains. The processes hitherto described for the preparation of the metal have been tried by the author without success The chloride or nitride is placed in a platinum boat and heated in a porcelain tube, through which a current of pure hydrogen passes. The metal does not tarnish in the air at common temperatures, but burns with brilliant scintillations when thrown into a flame. When heated in air it oxidises, producing all the oxides $\mathrm{V}_{2} \mathrm{O}, \mathrm{V}_{2} \mathrm{O}_{2}, \mathrm{~V}_{2} \mathrm{O}_{3}, \mathrm{~V}_{2} \mathrm{O}_{4}$, and $\mathrm{V}_{2} \mathrm{O}_{5}$. It is not attacked by hydrochloric acid or dilute sulphuric acid. Hot strong sulphuric acid slowly dissolves it. It is violently oxidised by nitric acid, and slowly dissolved by hydrofluoric. The metal burns in chlorine, and when heated in nitrogen forms the mononitride.

$\Longrightarrow$

\section{DIARY}

THURSDAY, NOVEMBER 3.

LINNEAN SOciety, at 8. - On the Fertilisation of Orchids and Asclepiads Dr. Manse! Weale.-On a Solitary Bee from South Africa: Dr. Manse Weale.

ChemicAl Society, at 8. - On the Analysis of Cast-iron: Mr. A. H. Elliott. MONDAY, NOVEMBER 7 .

Royal INSTItUTION, at z. - Genexal Monthly Meeting.

LONDON INSTITUTION, at 4. - Chemistry: Prof. Odling. TUESDAY, NOVEMBER 8.

Ethnological Society, at 8.--On the Kimmerian and Atlantean Races: THNOLOGICAL SOCIETY, at 8.--On the Kimmerian and Atlantean Races: Mr. Hector McLean- - N rre on the name 'Aymara

WEDNESDAY, NOVEMBER 9.

Royal Microscopical Society, at 8. - Notes on the Minute Structure of certain Insect Scales: Mr. S. J. M'Intire

\section{THURSDAY, NOVEMBER YO.}

London Mathematical Society, at 8.-General Meeting. Retiring President's Address. Sketch of recent researches upon quartic and quintic surfaces.

\section{BOOKS RECEIVED}

ENGLish.-The Elements of Mechar.ism: T. M. Goodeve (Longmans).Papers on the Great Pyramid: J. V. Day (Edmonston and Doug as).

Foreign.-(Through Williams and Norgate)-Jahrbuch der Empfindungen: Hirzel und Gretschel.-Geometr sche See-proben: Dr. Boet.cher-für ' 'phthalmologie: Arit, Donders, und von Graeffe-Jahresberichi über die Fortschritte der Chemie.

\section{CONTENTS}

PAGE

The Government of the Royal Society

The Gelogy of The DIamond Fuelds of South Africa $\cdot \bullet \cdot \cdot$ QUARTERLY WeATHER REPort. By Professor BALFOUR STEWART, F.R.S.

BEET-ROOT SUGAR:

BEET-ROOT SUGAR: ${ }^{\circ}$

Dr. Balfour Stewart's Opening Lecture at Owens College, Manchester, - Lieut -C., Sening Lecture

The Elger; H. R. Proctor; Rev, R. MAin; J. J. HALL; C.

POCKLINGTON ; A. M. SMITH

The Aurura o Sept. 24.-G M. DAwSON
Hereditary Deformities.-W. FIELD

The Cefn Reptile and the Times. -W. Boyd Dawkins, Fis.

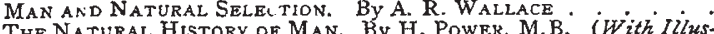
The Natural History of Man. By H. Power, M.B. (With Illustrations.)

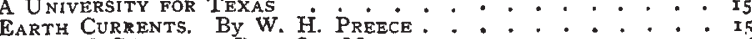

DR. C. W. GüMBEL ON DEEP-SEA MUD

The British Assoctation:-Sectional Prockedings: $: 0^{*}$ i 7 -20

Scientific Serials . . . * . . . . . . . . . . . 20

DLARY . . . . . . . . . . . . . . . . . . . . 20

Books Received . . . . . . . . . . . . 20

Errata.-Vol. ii., page 399, second column, line 18 from bottom, for "Electrometer" read "Anemometer." Page 5r2, second column, line from bottom, for "requirements" read "acquirem=nts." 